\title{
A time-series analysis of the relationship between urban layout and automobile reliance: have cities shifted to integration of land use and transport?
}

\author{
M. Taniguchi ${ }^{1}$, R. Matsunaka ${ }^{2}$ \& K. Nakamichi ${ }^{1}$ \\ ${ }^{I}$ Graduate School of Environmental Science, Okayama University, Japan \\ ${ }^{2}$ Graduate School of Engineering, Kyoto University, Japan
}

\begin{abstract}
Changes in land-use patterns and personal lifestyles, as influenced by motorization, have caused serious problems: decreased usage of public transportation, the decline of city centers, and increased fuel consumption. In developed countries, low-density urban areas are expanding: urban sprawl is continuing because of further urbanization. Results of several studies show that, through better land use and transportation integration, the compact urban layout is effective for reducing gasoline consumption and achieving a sustainable society. The relationship in major world cities between population density and energy consumption has already been analyzed in some studies using crosssection analysis. Furthermore, many studies undertaken since the late 1990s have described sustainable development through usage of a more compact urban layout. Actually, many municipalities have accepted and promote compact urban layout as a policy. However, a basic trend in the relationship between urban layouts and automobile reliance over a prolonged period has not been investigated considering recent time-series data.

This study is intended to identify the change in the relationship between automobile usage and urban layout factors, particularly population density, for the purpose of suggesting measures for land use and transport integration. Changes in automobile fuel consumption were calculated using data from Nationwide Person Trip Surveys (conducted in 1987, 1992, 1999, and 2005) for 38 Japanese cities (including local and metropolitan area cities). Subsequently, the relationship between automobile fuel consumption and factors such as city type and public transportation conditions was analyzed using multiple regression models. The results show an increase of low-density cities, in which residents are consuming much automobile fuel, implying that cities of dispersed (not compact) type are increasing. In addition, population density is not the only important factor that influences automobile usage.
\end{abstract}

Keywords: $\mathrm{CO}_{2}$ emission, automobile usage, population density, compact city. 


\section{Introduction}

Recently, increased $\mathrm{CO}_{2}$ emissions from transportation modes are especially conspicuous, especially in economically developed countries. Residents who walk or use public transport have become fewer than before, because the progress of motorization and the spread of cities have increasingly necessitated movement over large areas. In response, the discussion of $\mathrm{CO}_{2}$ reduction has been advanced through COP13, CMP3, IPCC, etc. The reduction of $\mathrm{CO}_{2}$ is now seen as an urgent international problem.

A compact urban layout might be the most important measure to reduce $\mathrm{CO}_{2}$ emissions and to solve problems arising from excessive reliance on the automobile. Adoption of such urban layouts has been advocated since the late 1970s. Thomson [1] was among the first researchers to address the relationship between an urban layout and its transportation network. Many studies conducted since the late 1980s have described that more compact urban layouts can support sustainable development. Newman and Kenworthy [2] examined the relationship between population density and gasoline consumption. Moreover, several studies have already examined the relationship between urban forms and residents' behavior, especially on a municipal scale, as opposed to a town scale: those of Jenks et al. [3], Naess [4], Roo and Miller [5], and Williams et al. [6]. Of those, Newman and Kenworthy [2] showed quantitatively the most basic information portraying a relation between urban structure and automobile use from real data, as shown in Fig. 1: cities in USA such as Sacramento, Los Angeles, and Chicago are located on the upper left of the graph; cities in Asia but outside of Japan, such as Hong Kong and Seoul, are located on the bottom right of the graph. The former cities have low population density and the residents have high energy consumption for transportation. The latter cities have high population density and low transportation energy consumption by residents. Cities in Europe and Japan almost invariably show values in the middle segment of the graph: the urban structure and car use conditions are similar. Information related to cities in Japan can serve as a reference when the relation between urban structure and a traffic environmental load is examined for cities in Europe.

Moreover, the change of the relation between population density and the traffic environmental load should be studied with the passage of time. Such knowledge of trends using data from previous surveys can be used along with the latest data for urban planning for the future. Nevertheless, fundamental information related to various cities' residents' $\mathrm{CO}_{2}$ emissions attributable to automobile use, and how those emission rates change remain unclear. Analyses of relationships between $\mathrm{CO}_{2}$ emissions and population density are important, as is an understanding of factors that influence $\mathrm{CO}_{2}$ emissions are useful for examination of population control and the urban traffic management: city scale, car ownership, public transportation service level, and city type aside from population density.

This study is intended to provide information for reference in cities in developed countries, excluding those in the USA, by clarifying the relation between $\mathrm{CO}_{2}$ emissions and population density as a representative index of the 


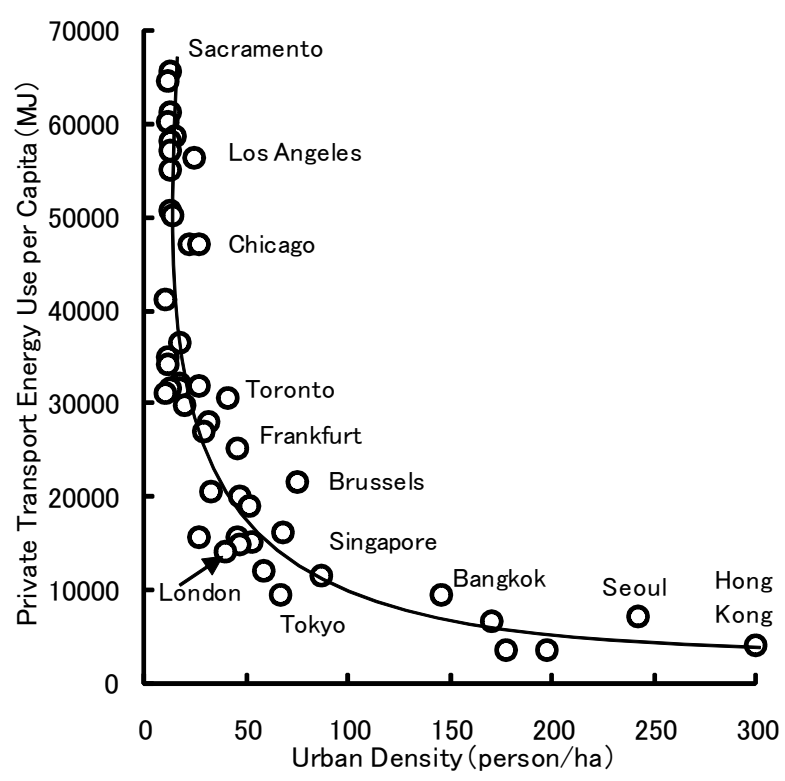

Figure 1: The relationship between transport energy consumption and urban density in principle cities (Newman and Kenworthy [2]).

urban structure in cities of Japan using the latest data and data of three prior surveys. Results of this study, obtained using a multiple regression model, also reveal factors affecting $\mathrm{CO}_{2}$ emissions, such as population density, in addition to conditions of car ownership, public transportation services, and regional characteristics.

\section{Advantages of this study}

In an earlier study using the data of National Person Trip Survey (NPTS) executed in 1992, Taniguchi \& Ikeda [7] modeled the influence that city characteristics exert on the automobile fuel consumption. Salient advantages of the present study over that earlier study are as follows:

1) This study uses $\mathrm{CO}_{2}$ as a traffic environmental load index. Its reduction has been recognized as important internationally since the Kyoto Protocol.

2) The relationship between city characteristics and $\mathrm{CO}_{2}$ emissions, as revealed by the four surveys in 1987, 1992, 1999 and 2005, is obtained using time series data for the same city and the same characteristics.

3) The $\mathrm{CO}_{2}$ emissions show different patterns in various cities where characteristics differ, including metropolitan areas and local areas.

4) Not only was the relationship between the population density and the amount of the $\mathrm{CO}_{2}$ emissions clarified; the change over time of the variables that influence the amount of the $\mathrm{CO}_{2}$ emissions was clarified using multiple regression analyses. 


\section{Data and samples}

In Japan, Metropolitan Person Trip Surveys (MPTS) have been conducted in major cities and metropolitan areas for the past three decades. They provide rich information, but are inappropriate for use here. This study requires trip data from many cities based on a single standard. Consequently, for this study, trip data from the National Person Trip Survey (NPTS) are used in preference to usual MPTS data. The Ministry of Land, Infrastructure, Transport and Tourism of Japan has conducted NPTS surveys four times: 1987, 1992, 1999, and 2005.

This survey is useful for comparison of time-series data of basic traffic characteristics of the cities; the survey was not originally executed for calculation of $\mathrm{CO}_{2}$ emission amounts. However, these data are useful for comparison of amounts of $\mathrm{CO}_{2}$ emissions among cities with time-series data according to the method devised for this study.

The subjects are 38 cities, which are classifiable into urbanization promotion areas and urbanization control areas, as depicted in Fig. 2. Zoning control in Japan is described in Table 1. The cities in Japan are roughly classifiable into areas of two kinds: metropolitan and local. Because the populations are larger than those of local areas, and because the infrastructure is advanced, cities in metropolitan areas that correspond to Japan's three major megalopolises (Tokyo, Osaka, and Nagoya) require separate treatment from those of cities in local areas. In this study, local cities are not a part of the three major metropolitan areas of Tokyo, Osaka, and Nagoya. Additionally, the cities are divided into central cities and satellite cities in the metropolitan areas. Central Cities in Metropolitan Area (CCMA) are government-designated cities or cities with a population of more than one million, and Satellite Cities in Metropolitan Area (SCMA) are the other cities in Japan's three major megalopolises. Local areas are classified as central cities, where various residential zones exist from the city center to suburbs in one city although their scale is smaller than those of metropolitan areas, and other local cities. Central Cities in Local Area (CCLA) are prefectural capital cities or cities with a population of more than 150,000 .

\section{Automobile $\mathrm{CO}_{2}$ emissions and population density}

\subsection{Method for estimation of automobile $\mathrm{CO}_{2}$ emissions}

Details of unlinked trips are not investigated in NPTS. This study targets automobile single trips and the mixed trips of automobile use and walking. The car single trips constitute the majority of the trips; it is a reasonable proxy for the amount of the car use. Consequently, about $98 \%$ of all car use trips were targeted in NPTS data of the surveys at four different points of time. The automobile fuel consumption for each unit distance was calculated using eqn. (1) in consideration of traffic congestion, etc., using the individual car velocity. The automobile $\mathrm{CO}_{2}$ emissions for each trip are calculated by multiplying each trip distance by $\mathrm{CO}_{2}$ emissions for each unit distance, as converted from automobile fuel consumption for each unit distance using eqn. (2). The per-capita automobile $\mathrm{CO}_{2}$ emissions 
Three major metropolitan areas

- Central City in Metropolitan Area (CCMA) 12 cities

- Satellite City in Metropolitan Area (SCMA) 8 cities

$\Delta \quad$ Central City in Local Area (CCLA) 13 cities

$\Delta \quad$ Local City in Local Area (LCLA) 5 cities

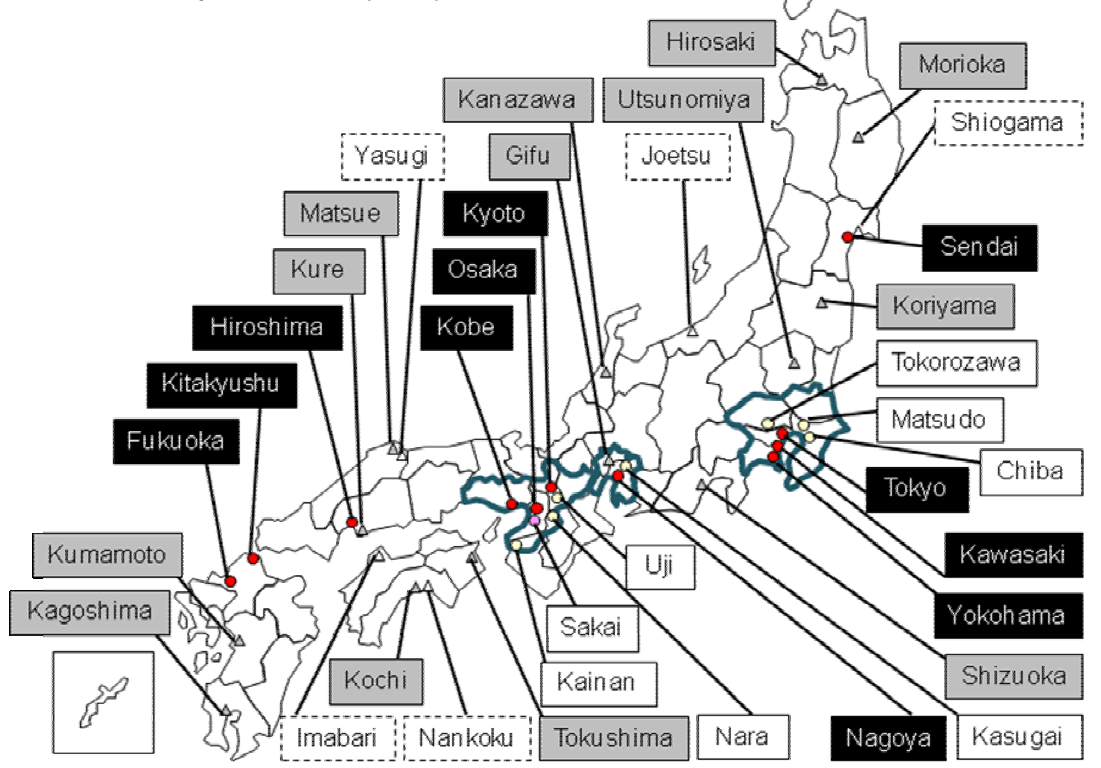

Figure 2: $\quad$ Sample Cities from National Person Trip Survey.

Table 1: Zoning control in Japan.

\begin{tabular}{l}
\hline \multicolumn{1}{c}{ Zoning control } \\
\hline Urbanization promotion area \\
Exclusively residential zone for low-height buildings (class 1) \\
Exclusively residential zone for low-height buildings (class 2) \\
Exclusively residential zone for high-and medium-height buildings (class 1) \\
Exclusively residential zone for high-and medium-height buildings (class 2) \\
Residential zones (class 1) \\
Residential zones (class 2) \\
Semi-residential zone \\
Neighborhood commercial zone \\
Commercial zone \\
Light-industrial zone \\
Industrial zone \\
Exclusively industrial zone \\
Urbanization control area
\end{tabular}


of each city were calculated by summing this result for each city, considered along with the number of samples of each city and each person's driving ratio. Both eqn. (1) and eqn. (2) were referred from Ohshiro et al. [8].

$$
\begin{aligned}
& F C=\frac{829.3}{v_{c}}-0.8572 v_{c}+0.007659 v_{c}^{2}+64.09 \\
& E F=E F_{0} \times H V \times F C
\end{aligned}
$$

$F C$ : automobile fuel consumption for each unit distance $(\mathrm{ml} / \mathrm{km})$

$v_{c}$ : velocity of car

$E F$ : automobile $\mathrm{CO}_{2}$ emissions for each unit of distance $\left(\mathrm{g}-\mathrm{CO}_{2} / \mathrm{km}\right)$

$E F_{0}: \mathrm{CO}_{2}$ emissions for each calorific value $\left(\mathrm{g}-\mathrm{CO}_{2} / \mathrm{J}\right)$

$H V$ : average calorific value $(\mathrm{J} / l)$

\subsection{Relationship between automobile $\mathrm{CO}_{2}$ emissions and population density}

Fig. 3 and Fig. 4 show the relationships between the amount of per-capita automobile $\mathrm{CO}_{2}$ emissions in respective cities on weekdays and the urbanization promotion area population densities in 1987 and 2005 by city type. Moreover, the temporal transition of the mean amount of automobile $\mathrm{CO}_{2}$ emissions and the urbanization promotion area population density according to city type are presented in Fig. 5. Salient implications of results of these analyses are as follows:

1) The amount of $\mathrm{CO}_{2}$ emissions has been influenced greatly by compactness (population density) in the city, as indicated by existing research.

2) Significant differences pertain among CCMA and SCMA cities in terms of population density and $\mathrm{CO}_{2}$ emission amounts. In contrast, the population density is low and $\mathrm{CO}_{2}$ emission amounts are high in both CCLA and LCLA.

3) The $\mathrm{CO}_{2}$ emissions continue to increase monotonously in each city type. This tendency is especially conspicuous in CCLA and LCLA cities.

\section{Relation between automobile $\mathrm{CO}_{2}$ emissions and city characteristics}

To elucidate the relation between automobile $\mathrm{CO}_{2}$ emissions and city characteristics more accurately, a multiple regression model is calibrated in each year. The dependent variable of this model is the natural logarithm value of the amount of per-capita automobile $\mathrm{CO}_{2}$ emissions. The independent variables are city characteristics such as population density, location, and conditions of public transportation. The selected variables are presented in Table 2 . The dummy of No. 2 denotes the car possession circumstances, and No. 3 shows the service level of a tram or a new traffic system in recent years: public transportation providing specialized service with high-frequency and over short distances between stations. Moreover, dummies No. 4, No. 5, and No. 6 represent cities that belong respectively to the three major megalopolises in Japan; No. 7 chiefly indicates a populous city of in a local area.

Parameters and $t$-values in Table 3 provide a clear representation of the relationship between urban forms and $\mathrm{CO}_{2}$ emissions as follows: 


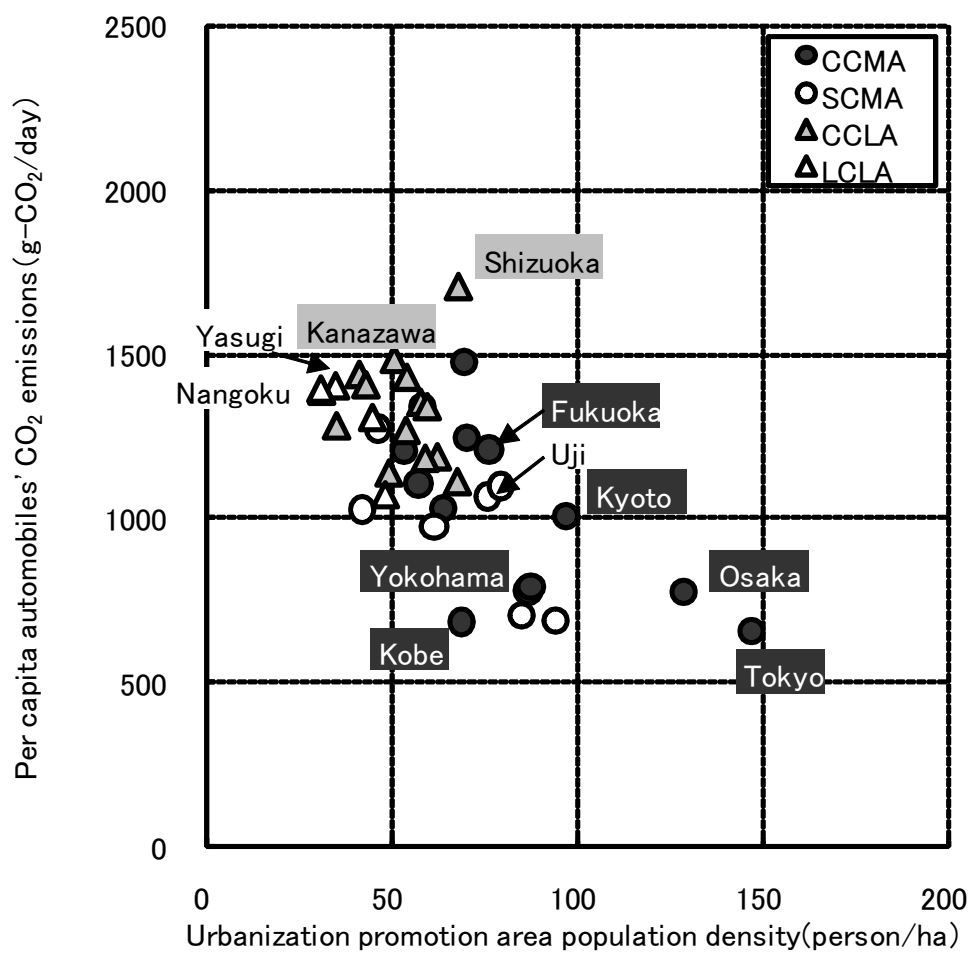

Figure 3: Relation between automobile $\mathrm{CO}_{2}$ emissions and population density in 1987.

1) High population density decreases the amounts of automobile $\mathrm{CO}_{2}$ emissions in each year, as described earlier in this paper.

2) Car ownership shows an almost direct connection with the amount of automobile $\mathrm{CO}_{2}$ emissions, although some unevenness is apparently attributable to age. On the other hand, the service level of public transportation infrastructure such as tram and new traffic systems, tends to lower the amount of automobile $\mathrm{CO}_{2}$ emissions.

3) Regarding the CCMA, the amount of per-capita automobile $\mathrm{CO}_{2}$ emissions is the lowest of all city types; the rate of increase is also low, as portrayed in Fig. 4. In this regard, however, compared to the other cities, in three major megalopolises in Japan, the tendency of car dependence has risen very much in the Nagoya metropolitan area, the headquarters of Toyota Motor Corp., as presented in Table 3.

4) Overall, the increase of the amount of per-capita automobile $\mathrm{CO}_{2}$ emissions of the cities in local area is considerable, as shown in Fig. 4. Especially, it is readily apparent that the car dependence tendency is remarkable from Table 3 in the passing age in the Prefectural capital cities, where cities are of typical size (population 300,000-700,000). 


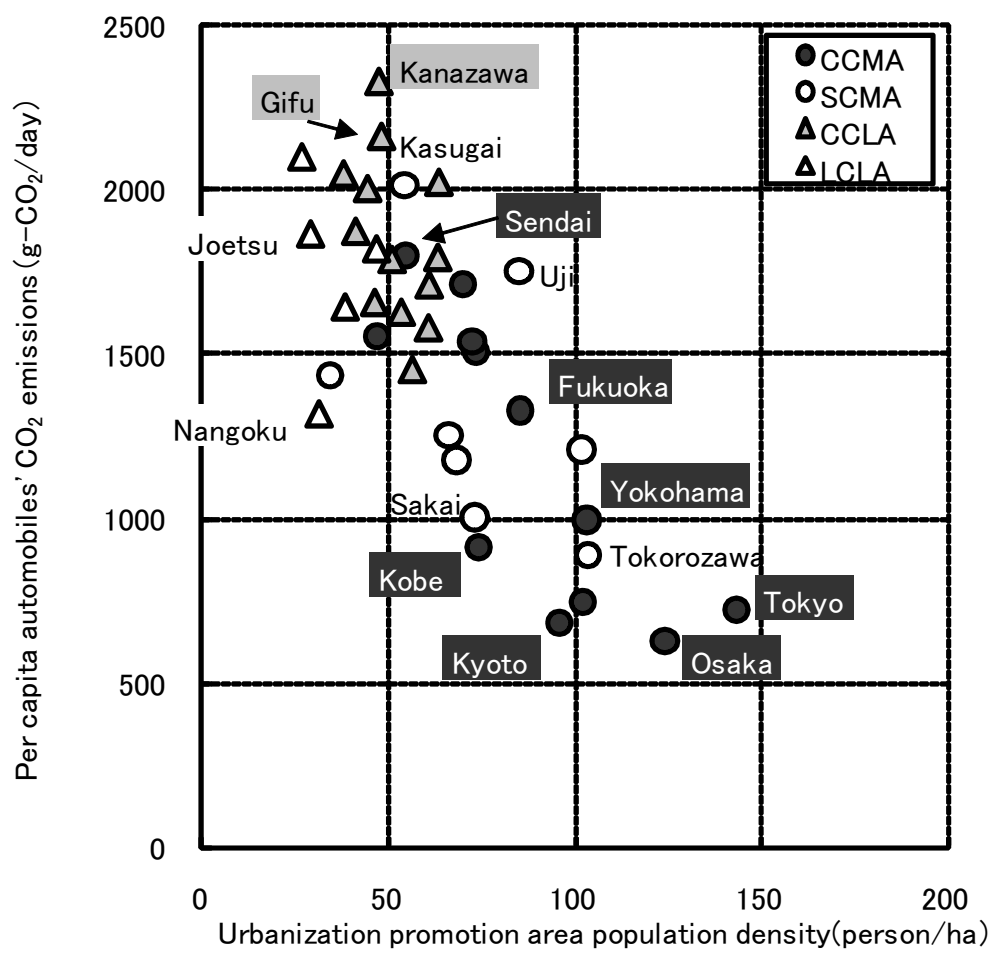

Figure 4: Relation between automobile $\mathrm{CO}_{2}$ emissions and population density in 2005 .

\section{Conclusion}

No city type shows a decrease in the amount of per-capita automobile $\mathrm{CO}_{2}$ emissions from 1987-2005. Achievement of reduction of $\mathrm{CO}_{2}$ attributable to transportation based on travel behavior of residents will require drastic changes. Results of this study portray a gradual increasing tendency of the amount of percapita automobile $\mathrm{CO}_{2}$ emissions in high-density cities where the urban structure has already been consolidated.

Consequently, the difference of the amount of per-capita automobile $\mathrm{CO}_{2}$ emissions between cities has increased. Efforts to reduce the amount of automobile $\mathrm{CO}_{2}$ emissions, especially in local cities, are necessary in the future through integration of land use planning and transport planning. The integration means to manage public transportation such as trams and new traffic systems with leading to high population density in the urbanization promotion areas. Results described in this paper are expected to be useful for European cities because European cities have an urban structure that was formed before the diffusion of automobiles. For that reason, they have much in common with Japanese cities from the viewpoint of urban structure. 


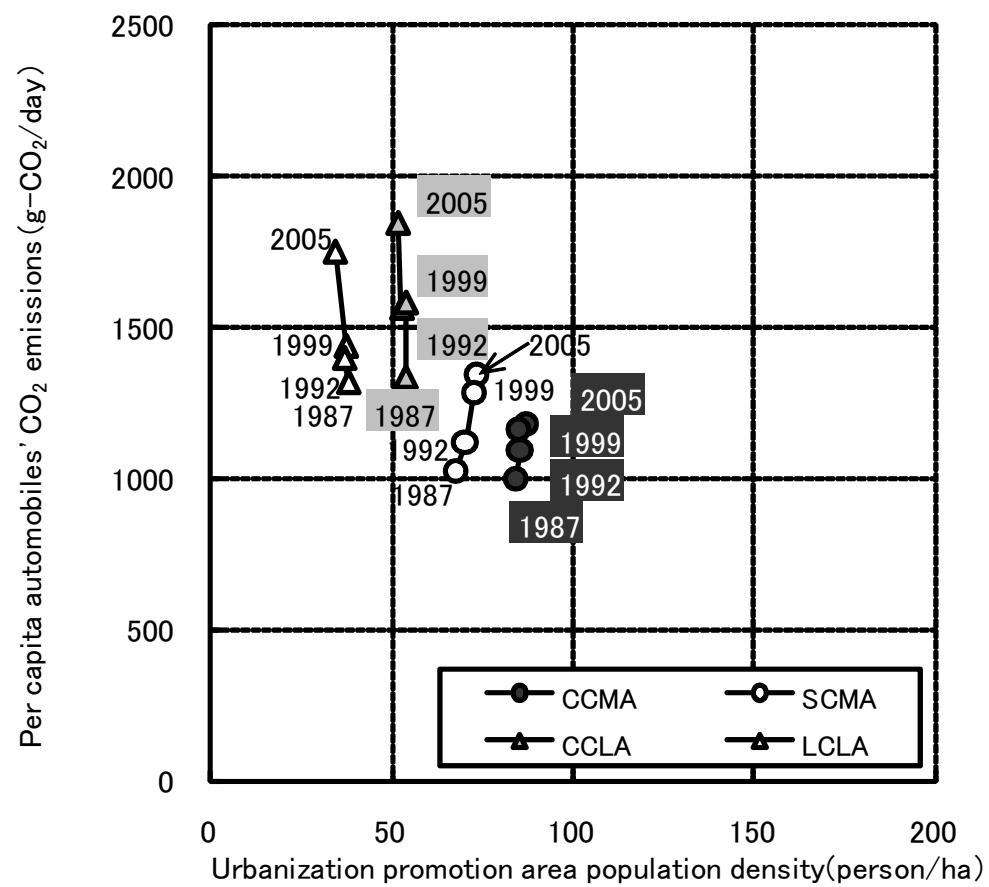

Figure 5: Age softening of relation between automobile $\mathrm{CO}_{2}$ emissions and population density (mean value according to city type).

Table 2: $\quad$ Definition of each value.

\begin{tabular}{l|c|l}
\hline \multicolumn{1}{c|}{ Category } & No. & \multicolumn{1}{c}{ Explanatory variable } \\
\hline Population & 1 & $\begin{array}{l}\text { Urbanization promotion area population density } \\
\text { (person/ha) }\end{array}$ \\
\hline Car ownership & 2 & $\begin{array}{l}\text { Number of automobiles per capita } \\
\text { (number/person) }\end{array}$ \\
\hline $\begin{array}{l}\text { Transportation } \\
\text { conditions }\end{array}$ & 3 & $\begin{array}{l}\text { Existence or nonexistence of tram or new traffic system }{ }^{*}(\mathrm{D})^{\star *} \\
\text { \{Sapporo, Tokorozawa, Tokyo, Yokohama, Gifu, Nagoya, Kyoto, } \\
\text { Osaka, Sakai, Kobe, Hiroshima, Kochi, Nangoku, Kitakyushu, } \\
\text { Kumamoto, Kagoshima\} }\end{array}$ \\
\hline City \\
characteristic
\end{tabular}

${ }^{\star}$ The dummy variable takes a value of 0 in 1987 in Yokohama, it is 1 in other years for that city. The dummy variable takes a value of 1 in 2005 in Nagoya, it is 0 in other years for that city. The dummy variable takes a value of 0 in 2005 in Gifu, it is 1 in other years for that city. **(D): Dummy variable 
Table 3: $\quad$ Factors that affect per-capita automobile $\mathrm{CO}_{2}$ emissions.

\begin{tabular}{|c|c|c|c|c|c|c|}
\hline \multirow[b]{2}{*}{ No. } & \multicolumn{3}{|c|}{1987} & \multicolumn{3}{|c|}{1992} \\
\hline & $\begin{array}{l}\text { Unstandardize } \\
\text { d parameter }\end{array}$ & $\begin{array}{l}\text { Standardize } \\
\text { d parameter }\end{array}$ & $t$-value & $\begin{array}{l}\text { Unstandardize } \\
\text { d parameter }\end{array}$ & $\begin{array}{l}\text { Standardize } \\
\text { d parameter }\end{array}$ & $t$-value \\
\hline 1 & -0.003 & -0.329 & $-2.321^{*}$ & -0.005 & -0.442 & -4.018 \\
\hline 2 & 1.285 & 0.290 & $2.165 *$ & 0.427 & 0.110 & 1.097 \\
\hline 3 & -0.043 & -0.084 & -0.788 & -0.038 & -0.072 & -0.907 \\
\hline 4 & -0.237 & -0.354 & -2.579 * & -0.183 & -0.255 & $-2.503 *$ \\
\hline 5 & -0.007 & 0.006 & 0.059 & 0.031 & 0.026 & 0.336 \\
\hline 6 & -0.097 & -0.145 & -1.116 & -0.209 & -0.292 & $-2.924 *$ \\
\hline 7 & 0.068 & 0.114 & 1.053 & 0.186 & 0.291 & 3.614 * \\
\hline Constant & 6.941 & - & 37.465 & 7.353 & - & 50.365 \\
\hline Adjusted $R^{2}$ & \multicolumn{3}{|c|}{0.688} & \multicolumn{3}{|c|}{0.832} \\
\hline \multirow[b]{2}{*}{ No. } & \multicolumn{3}{|c|}{$\overline{\overline{1999}}$} & \multicolumn{3}{|c|}{2005} \\
\hline & $\begin{array}{l}\text { Unstandardize } \\
\text { d parameter }\end{array}$ & $\begin{array}{l}\text { Standardize } \\
\text { d parameter }\end{array}$ & $t$-value & $\begin{array}{l}\text { Unstandardize } \\
\text { d parameter }\end{array}$ & $\begin{array}{l}\text { Standardize } \\
\text { d parameter }\end{array}$ & $t$-value \\
\hline 1 & -0.005 & -0.427 & -2.675 & -0.006 & -0.491 & $-2.336^{*}$ \\
\hline 2 & 2.003 & 0.543 & 3.670 * & -0.207 & -0.119 & -0.565 \\
\hline 3 & 0.056 & 0.105 & 1.012 & -0.144 & -0.207 & $-2.380 *$ \\
\hline 4 & -0.064 & -0.090 & -0.628 & -0.245 & -0.259 & $-2.040 * *$ \\
\hline 5 & -0.025 & -0.022 & -0.200 & 0.153 & 0.099 & 1.208 \\
\hline 6 & 0.083 & 0.117 & 0.918 & -0.342 & -0.362 & $-3.352 *$ \\
\hline 7 & 0.060 & 0.095 & 0.849 & 0.187 & 0.222 & 2.697 \\
\hline Constant & 6.650 & - & 24.831 & 7.959 & - & 19.256 \\
\hline Adjusted $R^{2}$ & \multicolumn{3}{|c|}{0.709} & \multicolumn{3}{|c|}{0.776} \\
\hline
\end{tabular}

\section{References}

[1] Thomson, J.M., Great cities and their traffic, Victor Gollancz, Ltd., 1977.

[2] Newman, P. \& Kenworthy, J., Sustainability and cities: overcoming automobile dependence, 1999.

[3] Jenks, M., Burton, E. \& Williams, K. (eds.), The compact city: A sustainable urban form? London: E \& FN Spon, 1996.

[4] Naess, P., Workplace location, modal split, and energy use for commuting trips. Urban Studies, 33(3), pp. 557-580, 1996.

[5] Roo, G. \& Miller, D. (eds.), Compact cities and urban development, Aldershot: Ashgate, 2000.

[6] Williams, K., Burton, E. \& Jenks, M. (eds.), Achieving a sustainable urban form, London: E \& FN Spon, 2000.

[7] Taniguchi, M. \& T. Ikeda, T., The compact city as a means of reducing reliance on the car: A model-based analysis for a sustainable urban layout, (Ed. by K. Williams), Spatial planning, urban form and sustainable transport, Ashgate, pp. 139-150, 2005.

[8] Ohshiro, N., Matsushita, M., Namikawa, R. \& Ohnishi, H., Fuel consumption and emission factors of carbon dioxide for motor vehicles. Civil Engineering Journal, 43(11), pp.50-55, 2001. (in Japanese) 